\title{
BMJ Open Association between perceived stress, multimorbidity and primary care health services: a Danish population-based cohort study
}

\author{
Anders Prior, Mogens Vestergaard, Karen Kjær Larsen, Morten Fenger-Grøn
}

To cite: Prior A, Vestergaard M, Larsen KK, et al. Association between perceived stress, multimorbidity and primary care health services: a Danish population-based cohort study. BMJ Open 2018;8:e018323. doi:10.1136/ bmjopen-2017-018323

- Prepublication history for this paper is available online. To view these files, please visit the journal online (http://dx.doi org/10.1136/bmjopen-2017018323).

Received 20 June 2017 Revised 6 December 2017 Accepted 26 January 2018

Check for updates

Research Unit for General Practice and Section for General Medical Practice, Department of Public Health, Aarhus University, Aarhus, Denmark

Correspondence to

Dr Anders Prior:

anders.prior@ph.au.dk

\section{ABSTRACT}

Objectives Mental stress is common in the general population. Mounting evidence suggests that mental stress is associated with multimorbidity, suboptimal care and increased mortality. Delivering healthcare in a biopsychosocial context is key for general practitioners (GPs), but it remains unclear how persons with high levels of perceived stress are managed in primary care. We aimed to describe the association between perceived stress and primary care services by focusing on mental health-related activities and markers of elective/acute care while accounting for mental-physical multimorbidity.

Design Population-based cohort study.

Setting Primary healthcare in Denmark.

Participants 118410 participants from the Danish National Health Survey 2010 followed for 1 year. Information on perceived stress and lifestyle was obtained from a survey questionnaire. Information on multimorbidity was obtained from health registers.

Outcome measures General daytime consultations, out-of-hours services, mental health-related services and chronic care services in primary care obtained from health registers.

Results Perceived stress levels were associated with primary care activity in a dose-response relation when adjusted for underlying conditions, lifestyle and socioeconomic factors. In the highest stress quintile, $6.8 \%$ attended GP talk therapy (highest vs lowest quintile, adjusted incidence rate ratios (IRR): $4.96,95 \% \mathrm{Cl} 4.20$ to 5.86), $3.3 \%$ consulted a psychologist (IRR: $6.49,95 \% \mathrm{Cl}$ 4.90 to 8.58$), 21.5 \%$ redeemed an antidepressant prescription (IRR: $4.62,95 \% \mathrm{Cl} 4.03$ to 5.31 ), $23.8 \%$ attended annual chronic care consultations (IRR: 1.22, $95 \% \mathrm{Cl} 1.16$ to 1.29 ) and $26.1 \%$ used out-of-hours services (IRR: $1.47,95 \% \mathrm{Cl} 1.51$ to 1.68). For those with multimorbidity, stress was associated with more out-ofhours services, but not with more chronic care services. Conclusion Persons with high stress levels generally had higher use of primary healthcare, 4-6 times higher use of mental health-related services (most often in the form of psychotropic drug prescriptions), but less timely use of chronic care services.

\section{INTRODUCTION}

Mental stress that does not fulfil the criteria for any psychiatric disorder is common in

\section{Strengths and limitations of this study}

- This is the first population-based cohort study to investigate the association between stress perception and primary healthcare utilisation while taking multimorbidity into account.

- A major strength of the study was the large cohort of 118410 participants in the Danish National Health Survey 2010 who answered questions on stress, lifestyle and socioeconomic factors.

- The participants' self-reported data were linked at the individual level with national health register information on multimorbidity status, vital status and primary care daytime and out-of-hours services, which ensured virtually no loss to follow-up.

- Multimorbidity was assessed by prospectively recorded register-based data on diagnoses and medication prescriptions for 39 mental and physical conditions.

- The limitations of this study include the lack of data on stress in non-respondents, the lack of data on private practising psychologists and no access to primary care medical records with details on the provided services and diagnoses.

the population. ${ }^{12}$ This type of mental stress has gained increasing attention because of the emerging evidence on its impact on the physical health; stress is highly associated with disease burden and physical multimorbidity (ie, two or more conditions in the same individual).$^{1-5}$ Persons with high stress levels have a poor prognosis of physical disease, for example, cardiovascular events and metabolic syndrome. ${ }^{6-8}$ Increased mortality rates are also seen, ${ }^{9}$ even after adjusting for mentalphysical multimorbidity. ${ }^{2}{ }^{10}$ Allostatic load theory constitutes a theoretical framework for physiological pathways that may explain these well-documented relations between mental and physical well-being. ${ }^{11} 12$

Mental health problems (including stress) and multimorbidity have been linked to highand potentially inappropriate-healthcare 
utilisation. This includes emergency contacts, unplanned admissions and potentially preventable hospitalisations. ${ }^{13-20}$ High perceived stress levels are inversely related to self-efficacy, which may affect the development of chronic conditions. ${ }^{21}$ Mental stress is an increasingly common reason for contacting the general practitioner (GP) ${ }^{22}$ but little is known about the services provided by GPs and other health professionals in primary care to persons with high levels of stress. In line with Anderson's behavioural model of healthcare utilisation, ${ }^{23}$ we hypothesised that high levels of perceived stress as a predisposing factor would increase the overall number of contacts to the GP, specifically the number of contacts related to mental health. We also hypothesised that the provided care would differ depending on the burden of mental and physical comorbidities. Mental symptoms may overshadow physical symptoms, and this may prevent adequate chronic care. ${ }^{24-26}$ High levels of perceived stress were thus hypothesised to be associated with poorer chronic care in those with multimorbidity.

We aimed to describe the association between the perceived stress level in the patients and the overall frequency of daytime and out-of-hours contacts, chronic care contacts and mental health-related contacts in primary care while taking into account multimorbidity as a potential confounder and a moderator of the stress effects.

\section{METHODS}

\section{Study population, design and setting}

The study population consisted of respondents (age $>25$ years) from the nationwide Danish National Health Survey of $2010 .{ }^{27}$ Survey questionnaires were collected by 1 May 2010 (index date). We excluded persons who died or emigrated before this date (2235 persons). A total of 118410 (response rate: $56 \%$ ) returned the questionnaire with information on all perceived stress items.

We conducted a population-based cohort study with up to 1 year of follow-up until death, emigration or end-ofstudy (1 May 2011), whichever came first. Using the personal identification number assigned to all Danish citizens, ${ }^{28}$ we linked individual-level data across survey responses and health registers. Almost all Danish citizens are listed with a GP providing them with universal tax-funded access to healthcare. ${ }^{29}$ The GP acts as a gatekeeper to secondary care and may refer to other publicly funded services in primary care. ${ }^{30}$ Referrals to private practising psychiatrists are fully covered by the healthcare system. Referrals to psychologists are partly covered if certain criteria are fulfilled, for example, a diagnosis of depression or anxiety, or loss of a first-degree relative, but not high perceived stress in itself.

Danish GPs are contractors in a partly per capita, partly fee-for-service remuneration system. ${ }^{31}$ The contract with the public healthcare system defines reimbursement fees for daytime consultations and out-of-hours services (typically from 16:00 to 08:00). Most medical work is covered by an unspecific base fee, but some specific services performed during the consultation, for example, talk therapy or psychometric testing, are additionally reimbursed. Annual chronic care consultations can be performed once a year for each chronic condition and are remunerated by a special fee. Invoices from the contractors are recorded in the Danish National Health Service Register, which provided us with data on all contacts and publicly reimbursed services performed by Danish GPs, psychologists and psychiatrists. ${ }^{32}$

Drug prescriptions are not recorded in the Danish National Health Service Register, but the Danish National Prescription Registry provided data on redeemed drug prescriptions based on data from all Danish pharmacies. ${ }^{33}$

\section{Perceived stress}

In the survey questionnaire, we measured perceived stress by Cohen's Perceived Stress Scale (PSS). ${ }^{34-36}$ The PSS has been widely used and psychometrically validated as a reliable measure of psychological stress. ${ }^{35} 36$ It is based on a five-level Likert-style questionnaire with items on general stress, coping and feeling of control. The 10-item Danish version produces a sum score of $0-40 ; 40$ points represent the highest perceived stress level. The PSS has no predefined cut-off values, ${ }^{34}$ but fifth quintile values are often considered abnormal. ${ }^{1}$ The stress score was, therefore, divided into quintiles to assess potential non-linear relations with outcomes.

\section{Multimorbidity}

The health status of each participant on the index date was assessed using a multimorbidity index of eight psychiatric and 31 physical long-term conditions (online supplementary eTable 1) identified in Danish nationwide health registers by a previously described algorithm. ${ }^{2}$ The algorithm combined data on diagnoses from all Danish hospitals and outpatient clinics with redeemed drug prescriptions from all Danish pharmacies. This approach is in line with recognised international measures of multimorbidity. ${ }^{37}$ No international consensus on the choice of multimorbidity indices exists, apart from some key diseases that are always included. ${ }^{38}$ Multimorbidity was defined as two or more coexisting conditions. ${ }^{40}$

\section{Outcomes}

Our main outcomes of interest were selected from the list of reimbursed services and redeemed drug prescriptions. These were categorised into three groups: (1) services related to mental health (GP talk therapy, GP psychometric tests and sessions with a publicly reimbursed private practising psychologist or psychiatrist) and redemption of psychotropic medication, (2) services in general practice related to elective chronic care (spirometry test for lung disease, blood sugar sampling for diabetes, ECGs, home blood pressure monitoring for cardiovascular disease and annual chronic care consultations (one annual review meeting per chronic disease per patient)) and (3) the overall rate of consultations based on the time of day, 
that is, daytime face-to-face consultations with GPs and out-of-hours services (telephone or face-to-face consultations with GP).

The service codes and 'Anatomical Therapeutic Chemical' medication codes used to identify the outcomes can be found in the online supplementary eTable 2).

\section{Other covariates}

Information on the highest achieved education level according to the Unesco classification system $(<10$ years, 10-15 years, $>15$ years of education), ${ }^{41}$ cohabitation status (single or cohabiting) and ethnicity (Danish, other western background, other) was obtained from Statistics Denmark. ${ }^{42}$ The Danish Civil Registration System provided information on sex, age (10-year age bands) and vital status (alive, dead or emigrated). ${ }^{28}$ Information on working status (currently employed or unemployed, students and retirees) and lifestyle factors (physical activity (light or no weekly activity, moderate activity $\geq 4$ hours weekly, hard activity $\geq 4$ hours weekly), body mass index (underweight $<18$, normal weight $18-25$, overweight 25-30, obese $>30$ ) and alcohol (drinks per week for men and women), smoking (never smoker, former smoker, current smoker) and dietary habits (unhealthy, medium, healthy)) was obtained from the survey.

\section{Statistical analysis}

Cumulative incidence proportions (CIPs), which reflect the proportion of persons with at least one contact at 1 year after the index date, and incidence rates (IRs), which reflect the total number of contacts during follow-up were calculated for all investigated primary care activities. We used a negative binomial regression model to calculate incidence rate ratios (IRRs) by PSS score quintiles and assigned the first PSS quintile as the reference. We then adjusted for sex, age as 10-year age bands and presence of each of the 39 conditions in the multimorbidity index, lifestyle factors and socioeconomic factors on the index date. We included the time at risk to account for death or emigration in both models. Cluster robust variance estimation was used to estimate $95 \%$ CI to account for interindividual heterogeneity. We imputed missing data on lifestyle and socioeconomic factors in a chained equations model of all our analysis parameters and produced 20 imputation sets. ${ }^{43}$ To assess the effect modification from disease burden, we stratified the analyses on the number of the 31 physical conditions of the multimorbidity index.

Three sensitivity analyses were performed to test the robustness of our results. First, we included in our analysis only persons without diagnosed psychiatric illness to separate the effect of perceived stress and symptoms related to psychiatric illness. Second, we performed a non-response analysis to test the generalisability of our findings; analyses of general primary care outcomes were carried out using register-based information on both survey respondents and non-respondents for which psychiatric illness acted as a proxy for stress (because the PSS score was unobtainable for non-respondents). Third, a complete case analysis, which excluded persons with missing data, was performed to validate the use of multiple imputations on missing values.

All analyses were performed using Stata V.13.1.

The study was performed in accordance with the Strengthening the Reporting of Observational Studies in Epidemiology guidelines.

\section{RESULTS}

The median age was 54 years (IQR: 23 years). The median PSS score was 11. Within the 1 year of follow-up, the study population was at risk for 117856 personyears. A total of 1042353 reimbursed primary care services and 85962 redeemed psychotropic prescriptions of interest were recorded. The perceived stress levels were generally higher for women and tended to increase with increasing number of physical conditions and presence of psychiatric morbidity (table 1). The distribution of survey variables across PSS quintiles has been reported elsewhere. ${ }^{2}$

\section{Perceived stress and primary care activities}

For all primary care activities, except home blood pressure monitoring, a dose-response relation seemed to exist between the perceived stress level and the probability of receiving a primary care service or psychotropic prescription during follow-up (tables 2 and 3, 1-year CIPs). The highest IRRs associated with perceived stress were found for mental health-related activities, but adjustments attenuated the association (table 2, IRRs). Among the highest stress quintile, $6.8 \%$ attended GP talk therapy (highest vs lowest PSS quintile; adjusted IRR: 4.96, 95\% CI 4.20 to 5.86 ), $3.3 \%$ consulted a psychologist (IRR: 6.49, $95 \%$ CI 4.90 to 8.58 ), $3.7 \%$ consulted a psychiatrist (IRR: $13.26,95 \%$ CI 8.33 to 21.09$), 21.5 \%$ redeemed an antidepressant prescription (IRR: $4.62,95 \%$ CI 4.03 to 5.31 ), $23.8 \%$ attended annual chronic care consultations (IRR: $1.22,95 \%$ CI 1.16 to 1.29 ) and $26.1 \%$ used out-of-hours services (IRR: $1.47,95 \%$ CI 1.51 to 1.68 ). The proportion of persons who visited their GP at least once during the follow-up year rose with increasing stress levels from $77 \%$ to $89 \%$ (table 3 ).

\section{Perceived stress and primary care activities by multimorbidity level}

The IRRs for receiving a mental health-related service generally remained stable across PSS quintiles, regardless of underlying disease count (figure 1, IRRs). However, in absolute terms, the use of talk therapy and psychologist services decreased and psychotropic drug prescriptions increased with increasing numbers of physical conditions (figure 1, 1-year CIP).

Nearly all persons with physical multimorbidity visited their GP during the investigated year. Multimorbidity in itself was associated with use of elective chronic care services, that is, annual chronic care consultations, 
Table 1 Study population characteristics according to PSS quintile

\begin{tabular}{|c|c|c|c|c|c|c|c|}
\hline \multirow[b]{3}{*}{ Characteristics } & \multirow[b]{3}{*}{ Total number } & \multirow[b]{2}{*}{ Total } & \multicolumn{5}{|c|}{ PSS quintile } \\
\hline & & & 1 & 2 & 3 & 4 & 5 \\
\hline & & Col \% & Row \% & Row \% & Row \% & Row \% & Row \% \\
\hline Median PSS score (range) & & & $4(0-6)$ & $9(7-10)$ & $12(11-13)$ & $15(14-17)$ & $21(18-40)$ \\
\hline \multicolumn{8}{|l|}{ Age groups, years } \\
\hline $25-34$ & 13881 & 11.7 & 23.2 & 24.9 & 23.6 & 14.1 & 14.2 \\
\hline $35-44$ & 22673 & 19.1 & 26.7 & 25.4 & 22.0 & 13.2 & 12.7 \\
\hline $45-54$ & 25272 & 21.3 & 28.5 & 25.0 & 21.1 & 12.8 & 12.6 \\
\hline $55-64$ & 26610 & 22.5 & 31.1 & 24.6 & 20.6 & 12.8 & 11.0 \\
\hline $65-74$ & 19982 & 16.9 & 31.1 & 23.5 & 20.6 & 14.7 & 10.0 \\
\hline$\geq 75$ & 9992 & 8.4 & 20.8 & 19.6 & 21.8 & 20.1 & 17.7 \\
\hline \multicolumn{8}{|l|}{ Sex } \\
\hline Men & 54968 & 46.4 & 26.1 & 24.8 & 17.7 & 16.5 & 14.8 \\
\hline Women & 63442 & 53.6 & 19.4 & 22.3 & 18.1 & 19.0 & 21.2 \\
\hline \multicolumn{8}{|l|}{ Number of conditions } \\
\hline 0 & 58718 & 49.6 & 25.6 & 26.3 & 18.9 & 16.5 & 12.7 \\
\hline 1 & 2,5755 & 21.8 & 22.2 & 22.9 & 17.8 & 18.1 & 18.9 \\
\hline 2 & 14677 & 12.4 & 21.1 & 21.5 & 17.3 & 18.6 & 21.6 \\
\hline$\geq 3$ & 19260 & 16.3 & 14.6 & 17.2 & 15.6 & 20.8 & 31.7 \\
\hline \multicolumn{8}{|l|}{ Any psychiatric condition } \\
\hline No & 109137 & 92.2 & 23.8 & 24.6 & 18.4 & 17.7 & 15.5 \\
\hline Yes & 9273 & 7.8 & 7.3 & 10.9 & 12.3 & 19.5 & 50.0 \\
\hline Total & 118410 & 100.0 & 22.5 & 23.5 & 18.0 & 17.8 & 18.2 \\
\hline
\end{tabular}

PSS, Perceived Stress Scale.

blood sugar measures, ECGs and home blood pressure monitoring (figure 2). In those with multimorbidity, higher stress levels were not associated with more elective chronic care services than lower stress levels. In absolute numbers, the use of chronic care services tended to decrease with increasing stress level. Stress was generally associated with use of acute out-of-hours services, regardless of multimorbidity level, but those with multimorbidity tended to have higher use (figure 2).

\section{Sensitivity analyses}

Excluding persons with psychiatric illness from the analyses did not change the overall pattern of primary care activities (online supplementary eTable 3 ). The non-response analyses showed that survey non-respondents more often were men and mentally ill $(\mathrm{P}<0.001)$ and less often used daytime consultations and services related to chronic care (online supplementary eTable $4)$. The adjusted IRRs of general primary care services were similar, regardless of response status when using psychiatric illness as a proxy for high levels of perceived stress (online supplementary eTable 5). The complete case analysis showed virtually no differences from our main analysis with multiple imputed data (data not shown).

\section{DISCUSSION}

\section{Summary of findings}

This population-based cohort study showed that the primary care activities increased with increasing perceived stress levels, even after adjusting for co-existing mental and physical conditions, lifestyle and socioeconomic factors. However, in absolute numbers few persons with high levels of perceived stress used mental health services, and more persons received psychotropic medication prescriptions than talk therapy. The rate of preventive services, for example, annual chronic care consultations and disease monitoring tests, did not increase with increasing stress levels in persons with multimorbidity. Most persons with high stress levels were in contact with their GP during the investigated year and had higher use of out-of-hours services than those with low stress levels.

\section{Strengths and limitations}

This study was based on unique information on stress levels and lifestyle factors in a large random sample of the Danish background population. The Danish Civil Registration System $^{28}$ allowed us to link information across healthcare registers and ensured no loss to follow-up.

Non-respondents tended to be different from survey respondents. Therefore, the absolute number of contacts 
Table 2 CIPs and IRRs of mental health-related primary care activities according to PSS quintile

\begin{tabular}{|c|c|c|c|c|c|c|c|}
\hline Primary care service & PSS quintile & $\mathrm{CIP}_{1 \mathrm{y}}(\%)$ & $95 \% \mathrm{Cl}$ & IR & Crude IRR & Adj. IRR* & $95 \% \mathrm{Cl}$ \\
\hline \multirow[b]{4}{*}{ Talk therapy by GP } & 1 & 1.1 & 1.0 to 1.2 & 0.02 & 1 & 1 & Reference \\
\hline & 2 & 1.7 & 1.5 to 1.8 & 0.03 & 1.48 & 1.38 & 1.15 to 1.65 \\
\hline & 4 & 3.1 & 2.9 to 3.3 & 0.06 & 2.76 & 2.38 & 1.99 to 2.83 \\
\hline & 5 & 6.8 & 6.5 to 7.2 & 0.15 & 6.90 & 4.96 & 4.20 to 5.86 \\
\hline \multirow[b]{4}{*}{ Psychometric tests } & 2 & 1.8 & 1.6 to 1.9 & 0.02 & 1.38 & 1.26 & 1.06 to 1.51 \\
\hline & 3 & 2.5 & 2.3 to 2.7 & 0.04 & 2.04 & 1.75 & 1.46 to 2.10 \\
\hline & 4 & 3.2 & 2.9 to 3.4 & 0.05 & 2.82 & 2.16 & 1.82 to 2.56 \\
\hline & 5 & 6.6 & 6.2 to 6.9 & 0.10 & 5.96 & 3.68 & 3.11 to 4.35 \\
\hline \multirow[t]{3}{*}{ Psychologist services } & 1 & 0.4 & 0.4 to 0.5 & 0.02 & 1 & 1 & Reference \\
\hline & 4 & 1.5 & 1.4 to 1.7 & 0.08 & 3.53 & 3.07 & 2.26 to 4.16 \\
\hline & 5 & 3.3 & 3.1 to 3.6 & 0.21 & 8.69 & 6.49 & 4.90 to 8.58 \\
\hline \multirow[b]{5}{*}{ Psychiatrist services } & 1 & 0.2 & 0.1 to 0.3 & 0.01 & 1 & 1 & Reference \\
\hline & 2 & 0.3 & 0.3 to 0.4 & 0.02 & 2.17 & 1.96 & 1.16 to 3.32 \\
\hline & 3 & 0.5 & 0.4 to 0.6 & 0.03 & 3.20 & 1.92 & 1.07 to 3.46 \\
\hline & 4 & 0.9 & 0.8 to 1.0 & 0.06 & 6.86 & 4.61 & 2.77 to 7.69 \\
\hline & 5 & 3.7 & 3.4 to 4.0 & 0.24 & 28.74 & 13.26 & 8.33 to 21.09 \\
\hline \multirow{2}{*}{ Antidepressants prescriptions } & 1 & 2.6 & 2.4 to 2.8 & 0.10 & 1 & 1 & Reference \\
\hline & 2 & 3.7 & 3.5 to 3.9 & 0.16 & 1.55 & 1.28 & 1.09 to 1.49 \\
\hline \multirow[b]{2}{*}{ Anxiolytics prescriptions } & 4 & 4.1 & 3.8 to 4.4 & 0.13 & 4.27 & 2.56 & 2.16 to 3.03 \\
\hline & 5 & 9.4 & 9.0 to 9.8 & 0.46 & 14.52 & 4.73 & 4.03 to 5.54 \\
\hline \multirow[b]{5}{*}{ Hypnotics prescriptions } & 1 & 3.4 & 3.2 to 3.6 & 0.08 & 1 & 1 & Reference \\
\hline & 2 & 4.3 & 4.0 to 4.5 & 0.11 & 1.39 & 1.34 & 1.18 to 1.51 \\
\hline & 3 & 5.3 & 5.0 to 5.6 & 0.16 & 2.03 & 1.67 & 1.47 to 1.89 \\
\hline & 4 & 6.6 & 6.3 to 7.0 & 0.22 & 2.77 & 1.83 & 1.61 to 2.07 \\
\hline & 5 & 11.0 & 10.6 to 11.5 & 0.5 & 6.32 & 2.93 & 2.59 to 3.31 \\
\hline
\end{tabular}

*Adjusted for sex, age as 10-year age bands, presence of each of the 39 psychiatric and physical conditions in the multimorbidity index, socioeconomic factors and lifestyle on index date.

$\mathrm{CIP}_{1 \mathrm{y}}$, Cumulative incidence proportion at 1 year (in \%); GP, general practitioner; IR, incidence rate; IRR, incidence rate ratio; PSS, Perceived Stress Scale.

to primary healthcare in our study may not be generalisable to the whole population. However, we have no reason to believe that response status affected the adjusted association between perceived stress and use of primary healthcare as the service use was similar among respondents and non-respondents using a proxy for stress.

Both definition and measurement of stress depend on the chosen recognised stress paradigm of which several exist. Stress can be seen as a fairly objective external factor and measured as the perceived magnitude and duration of a specific stressor, such as a stressful life event or long-term work stress exposure. ${ }^{44}$ Another approach is to assess stress through stress hormone levels and physiological responses to stress in the body. ${ }^{11}$ In this study, we approached mental stress as a subjective self-reported state reflecting the balance between perceived stressful events 


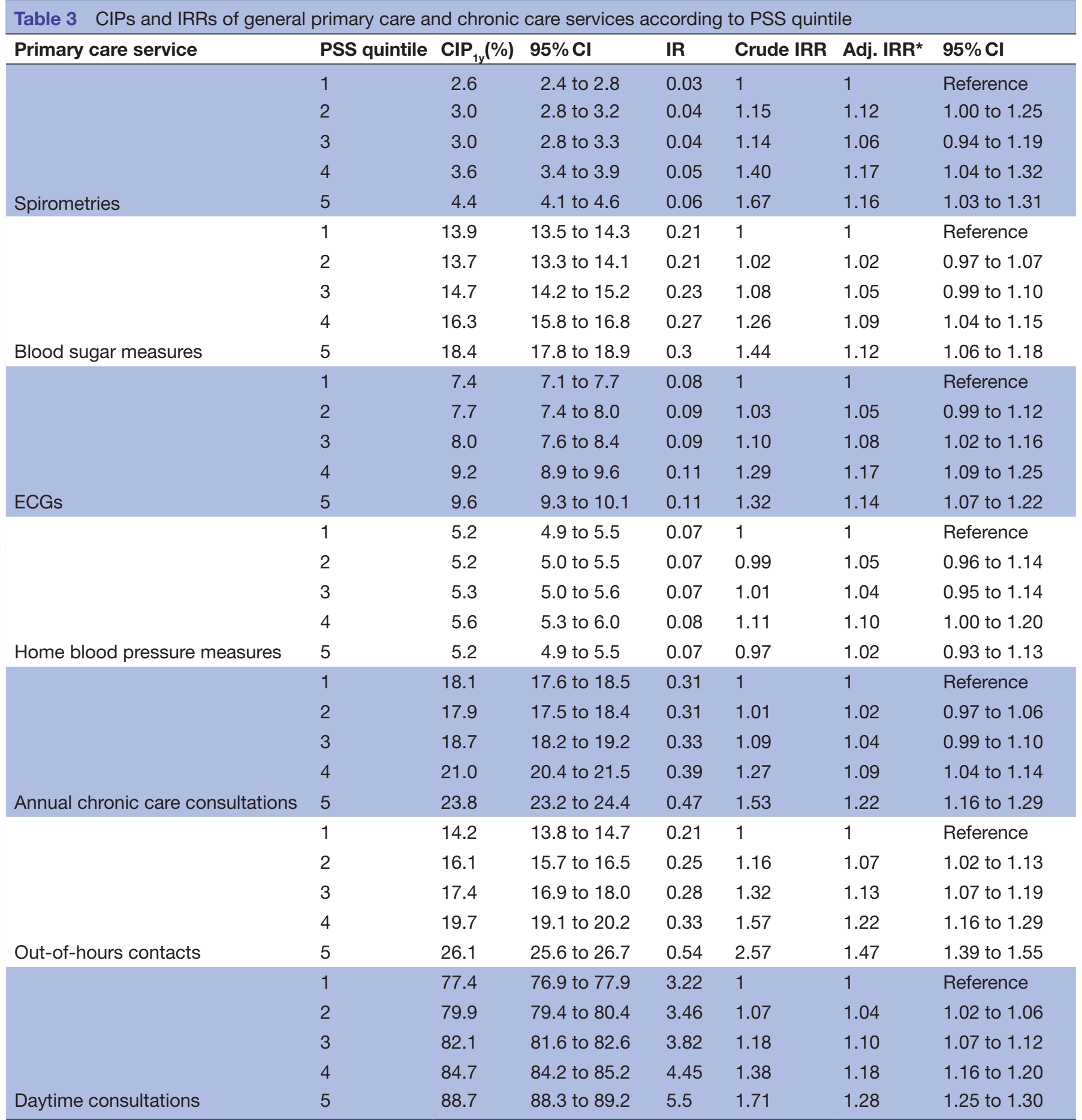

*Adjusted for sex, age as 10-year age bands, presence of each of the 39 psychiatric and physical conditions in the multimorbidity index, socioeconomic factors and lifestyle on index date.

$\mathrm{CIP}_{1 y}$, cumulative incidence proportion at 1 year (in \%); IR: incidence rate; IRR, incidence rate ratio; PSS, Perceived Stress Scale .

and individual coping mechanisms. ${ }^{45}$ This paradigm recognises that adaptation to stress is subject to numerous individual factors, including genetic predisposition and social context. The allostatic load theory synthesises the above-mentioned stress paradigms in a theoretical framework focusing on the dynamic adaptation to stress over time. ${ }^{46}$ Assessing perceived stress through a survey at one point in time has an important limitation; we do not know for how long the observed stress level has been present, but the PSS seems to remain fairly stable over time. ${ }^{47}$

Danish health register data are prospectively recorded and validated; these data are considered to be of high quality. ${ }^{28} 3233$ All GPs report their patients' service use, and all pharmacies report redeemed prescriptions. ${ }^{29}$ As reporting of primary care services is economically incentivised, high completeness is expected. ${ }^{32}$ Reporting may 

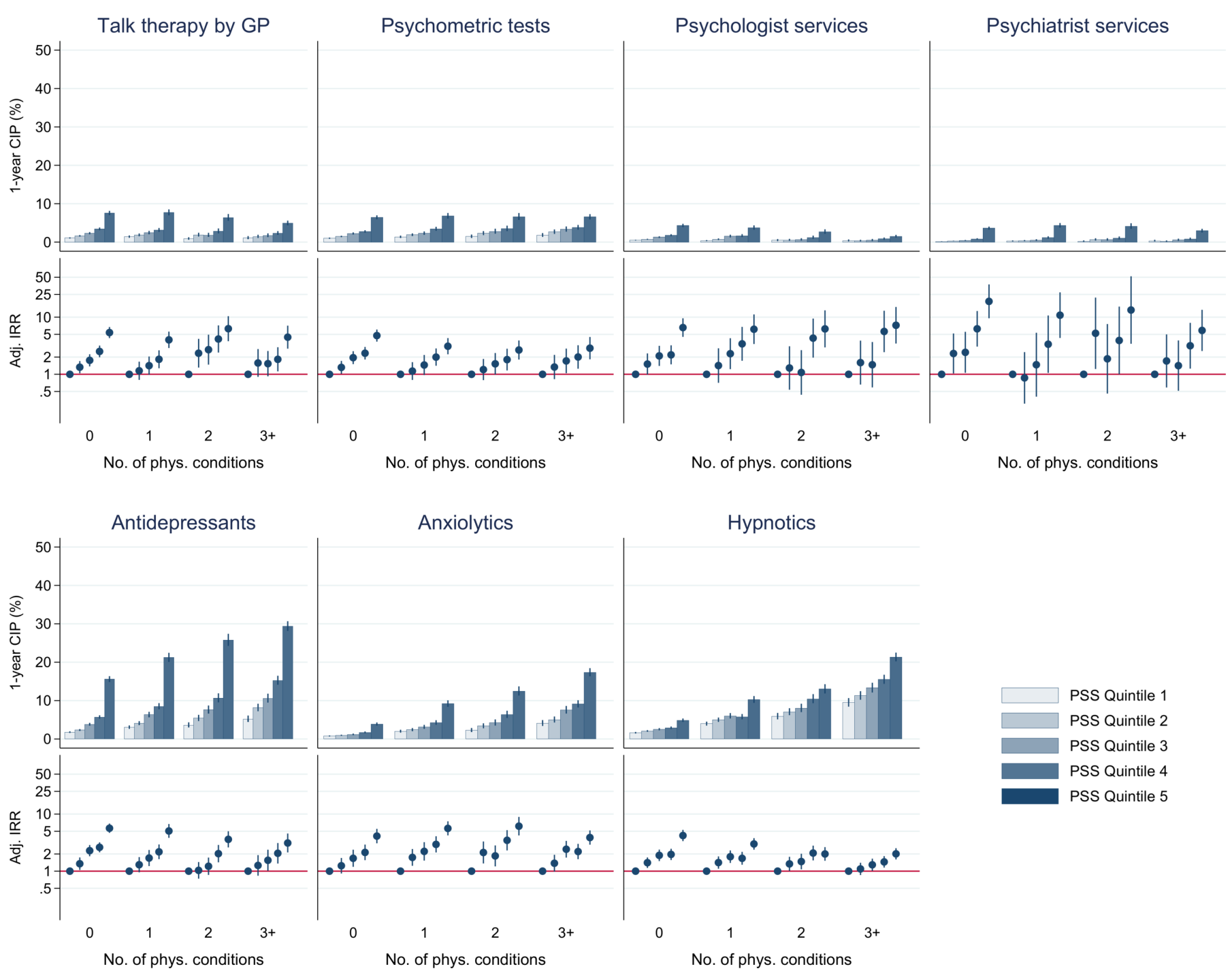

Figure 1 Cumulative incidence proportions (CIPs) and incidence rate ratios (IRRs) of mental health-related primary care services according to Perceived Stress Scale quintile and number of physical conditions. GP, general practitioner.

be incomplete if the GP forgets to register a service (eg, talk therapy). However, the GP's reporting is probably unaffected by patient stress levels; a potential misclassification is thus non-differential. Patients with more severe or complicated chronic disease may be followed in outpatient clinics and have fewer GP chronic care visits. If stress level was a marker of disease severity, this may explain the lack of association between stress and chronic care services among persons with multimorbidity. Psychologist services are probably well recorded in the health registers for reimbursement purposes, whereas visits paid by, for example, insurance companies and municipal or private organisations are not; the use of psychologists may hence be underestimated in our study.

Multimorbidity status was assessed at the time of the survey by using an algorithm of prospectively collected register data for up to 15 years before baseline. ${ }^{2}$ The lack of a Danish register for primary care diagnoses meant that multimorbidity status was based on outpatient and hospital discharge diagnoses combined with recordings of repeated prescriptions. This provided us with information on chronic conditions that were commonly managed in primary care, but the capture may not be complete. ${ }^{2}$ Psychiatric diagnoses were based on contacts to the psychiatric hospitals and outpatient clinics combined with prescriptions of psychotropic drugs; there may be a general under-recognition of psychiatric conditions in primary care, and the distinction between stress and depression may vary among GPs. ${ }^{48}$

The combined data sources from the survey and registers allowed us to adjust for demographic, lifestyle and socioeconomic confounders that are known to be associated with perceived stress. ${ }^{2}$ Adjusting tended to attenuate associations, but most outcome estimates remained significantly associated with the level of perceived stress. Some adjustment variables could be intermediate variables. Adjusting for them would underestimate the true association, but we chose this approach as it yields the most conservative estimates. ${ }^{49}$

For this type of epidemiological study, we lacked detailed GP records data to examine the context of the treatment and to conclude which specific factors in the 

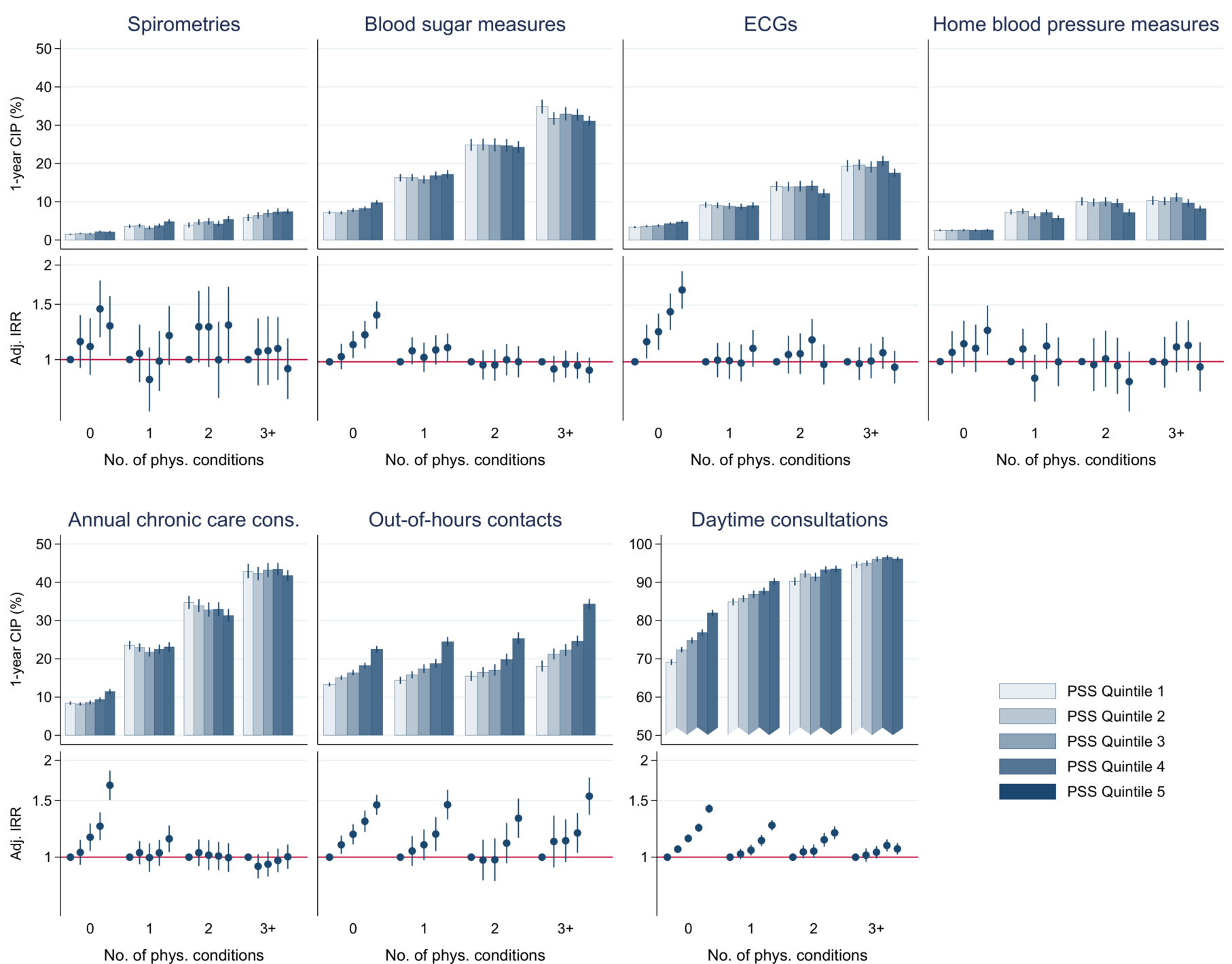

Figure 2 Cumulative incidence proportions (CIPs) and incidence rate ratios (IRRs) of general primary care and chronic care services according to Perceived Stress Scale (PSS) quintile and number of physical conditions.

patient, the doctor and the healthcare system are most likely to cause the observed findings.

\section{Comparison with existing literature}

To our knowledge, this is the first study to describe links between specific primary care services and level of stress as perceived by the patient. Existing evidence on the association between mental health and primary healthcare use is generally in line with our findings: psychosocial factors, ${ }^{50}$ mental health problems ${ }^{51-53}$ and illness perception ${ }^{54}$ are associated with frequent GP attendance even after accounting for the strong association between mental illness and physical health. ${ }^{55-57}$ Multimorbidity is expected to increase both the number of primary care consultations and the general prescription rate, ${ }^{58-60}$ which is also confirmed by our study. The effect of multimorbidity on healthcare consumption may be modified by personal factors that are known to be associated with appraised stress level, for example, gender, age and continuity of care. ${ }^{61}$
The finding that stress may lead to less timely chronic care is supported by the literature on mental-physical multimorbidity; a combination of psychiatric and physical conditions seems to hinder sufficient consultation time, impose errors and impair the general quality of chronic care in primary care. ${ }^{6263}$ High utilisation of out-of-hours services and unscheduled care have been described in patients with mental health problems including stress, ${ }^{20}$ specifically in patients with chronic conditions, although disease burden or severity may confound the association. ${ }^{19}{ }^{64}$ In our study, we had the statistical power to take into account the confounding factor of multimorbidity to counter this.

\section{Implications for research and practice}

Stress appraisal was positively related to primary care activity level, regardless of mental and physical disease burden. However, the interpretation of appropriateness is difficult. A high level of perceived stress in itself does not justify a psychiatric diagnosis. As no official guidelines 
exist for non-syndromic stress in general practice, we cannot conclude whether the level of mental health-related activities is appropriate. Interestingly, the treatment frequency was higher for antidepressants than for talk therapy provided by GPs or psychologist services. This tendency was stronger for persons with the highest stress levels and multimorbidity, especially three or more physical conditions. The underlying explanation for this association remains unknown, but persons with stress and physical multimorbidity may have a lower surplus of mental resources to interact in psychological treatment, or the complexity of health problems makes the GP decide to use the less resource-demanding pharmacological treatment. Yet, these treatment choices may be in contrast to the more general approach to mental health problems: Danish and international treatment guidelines recommend stepped care, where psychoeducation and psychosocial or psychological interventions are the first steps of choice before pharmacological treatment. ${ }^{65} 66$ However, we had no means to assess the exact treatment history and the duration of the appraised level of stress in this study. Therefore, patients with multimorbidity may already have tried a number of treatment options if they have had stress for a longer period of time.

In the literature, high stress levels in patients with multimorbidity are associated with suboptimal care and adverse outcomes, for example, more potentially preventable hospitalisations and high mortality. ${ }^{2} 18$ In our study, high stress levels were not associated with higher use of preventive chronic care services for those with severe multimorbidity; more chronic care services than observed would be expected and considered appropriate in those with high stress levels. This potential undertreatment or lack of timely chronic disease management in persons with mental-physical multimorbidity may play a role in the explanation of adverse outcomes. Conversely, highly stressed persons requested acute out-of-hours services more often than the less stressed, which is generally seen as a less desirable contact pattern for chronic disease management. ${ }^{67}$

The appropriate number of GP contacts and prescriptions for certain disease combinations cannot be deducted from our data because no information was available on the individual's full medical complexity, self-efficacy and social network. However, persons with high stress levels seemed to have a less timely appropriate use of primary care services. This, in addition to a poorer prognosis, calls for more focus on the mental well-being of patients even when no psychiatric illness is diagnosed. This also underlines the importance of the psychological aspect in the biopsychosocial approach to treatment of persons with multimorbidity.

The PSS measures an independent stress construct and was originally intended as a one-dimensional scale without predefined cut-off values. ${ }^{34}$ The value of the score may not be easily interpretable in a clinical setting, and caseness is difficult to operationalise. Stress symptoms are common in psychiatric disorders and overlaps exist, which is also reflected in the correlation between measurements of stress, depression and anxiety. ${ }^{36} 6869$ However, directing the focus away from diagnoses has important strengths, for example, less stigmatisation and reduced focus on pharmacological treatment. No validated clinical instrument is available for stress screening in general practice, and it is uncertain if screening is a good solution. Additionally, the GP may not be able to offer patients with stress much treatment as no well-developed management guidelines exist. More importantly, the time frame and setting in which the GP meets the patient should support the assessment of the patient's mental well-being and resources. This can be challenging for the GPs in patients with multimorbidity, where the treatment is multifaceted, and care is strongly affected by psychosocial factors. ${ }^{70}$ Models of collaborative and integrated care aim to redefine the GP consultation and focus more on empowering patients with co-existing mental and physical health problems. ${ }^{71} 72$ Patient-centred care is essential in achieving this goal. ${ }^{73}$ Stress-alleviating interventions may improve the prognosis if the association between perceived stress and adverse outcomes is causal. Mindfulness-based stress reduction and problem-solving therapy could play a role. ${ }^{756}$

Mental stress and multimorbidity are common problems that often coexist in the general population. Therefore, even a small impact of stress on the prognosis and general healthcare utilisation may be relevant in public health. Future research should explore potential management strategies and preventive interventions aimed at patients with mental stress. Patient-centred care research and qualitative research conducted in primary care may provide some new answers to these questions.

Acknowledgements Data support was given by the National Centre for RegisterBased Research, Aarhus BSS, Aarhus University, Denmark.

Contributors AP, MF-G, KKL and MV conceived the study. Data collection and analyses were mainly done by AP and MF-G. AP wrote the first draft. All authors contributed to the interpretation of data, the preparation of the manuscript and approved the final version.

Funding This work was supported by an unrestricted grant (grant number: R1552012-11280) from the Lundbeck Foundation (MEPRICA), by the Program for Clinical Research Infrastructure (PROCRIN) established by the Lundbeck Foundation and the Novo Nordisk Foundation and administered by Danish Regions, and by the Central Denmark Region Foundation for Primary Health Care Research. The Danish Health Profile 2010 was funded by the Capital Region of Denmark, Region Zealand, the Region of Southern Denmark, the Central Denmark Region, the North Denmark Region, the Danish Ministry of Interior and Health and the National Institute of Public Health at the University of Southern Denmark.

Disclaimer The funding sources had no role in the design and conduct of the study; collection, management, analysis and interpretation of the data; and preparation, review or approval of the manuscript.

Competing interests None declared.

Patient consent Detail has been removed from this case description/these case descriptions to ensure anonymity. The editors and reviewers have seen the detailed information available and are satisfied that the information backs up the case the authors are making.

Ethics approval This study was approved by Danish Data Protection Agency (record number 2013-41-1719).

Provenance and peer review Not commissioned; externally peer reviewed. 
Data sharing statement № additional data available.

Open Access This is an Open Access article distributed in accordance with the Creative Commons Attribution Non Commercial (CC BY-NC 4.0) license, which permits others to distribute, remix, adapt, build upon this work non-commercially, and license their derivative works on different terms, provided the original work is properly cited and the use is non-commercial. See: http://creativecommons.org/ licenses/by-nc/4.0/

(C) Article author(s) (or their employer(s) unless otherwise stated in the text of the article) 2018. All rights reserved. No commercial use is permitted unless otherwise expressly granted.

\section{REFERENCES}

1. Nielsen L, Curtis T, Kristensen TS, et al. What characterizes persons with high levels of perceived stress in Denmark? A national representative study. Scand J Public Health 2008;36:369-79.

2. Prior A, Fenger-Grøn M, Larsen KK, et al. The association between perceived stress and mortality among people with multimorbidity: a prospective population-based cohort study. Am J Epidemiol 2016;184:199-210.

3. Keller A, Litzelman K, Wisk LE, et al. Does the perception that stress affects health matter? The association with health and mortality. Health Psychol 2012;31:677-84.

4. Fortin M, Bravo G, Hudon C, et al. Psychological distress and multimorbidity in primary care. Ann Fam Med 2006:4:417-22.

5. Van Den Akker M, Buntinx F, Knottnerus JA. Comorbidity or multimorbidity: What's in a name? A review of literature. Eur $J$ Gen Pract 1996;2:65-70.

6. Stansfeld SA, Fuhrer R, Shipley MJ, et al. Psychological distress as a risk factor for coronary heart disease in the Whitehall II Study. Int $J$ Epidemiol 2002;31:248-55.

7. Kivimäki M, Virtanen $M$, Elovainio $M$, et al. Work stress in the etiology of coronary heart disease--a meta-analysis. Scand J Work Environ Health 2006;32:431-42.

8. Chandola T, Brunner E, Marmot M. Chronic stress at work and the metabolic syndrome: prospective study. BMJ 2006;332:521-5.

9. Russ TC, Stamatakis E, Hamer M, et al. Association between psychological distress and mortality: individual participant pooled analysis of 10 prospective cohort studies. BMJ 2012;345:e4933.

10. Prior A, Fenger-Grøn M, Davydow DS, et al. Bereavement, multimorbidity and mortality: a population-based study using bereavement as an indicator of mental stress. Psychol Med 2017:1-9.

11. Stratakis CA, Chrousos GP. Neuroendocrinology and pathophysiology of the stress system. Ann N Y Acad Sci 1995;771:1-18.

12. McEwen BS. Protective and damaging effects of stress mediators. $N$ Engl J Med 1998;338:171-9.

13. Mitchell SE, Paasche-Orlow MK, Forsythe SR, et al. Post-discharge hospital utilization among adult medical inpatients with depressive symptoms. J Hosp Med 2010;5:378-84.

14. Davydow DS, Fenger-Grøn M, Ribe AR, et al. Depression and risk of hospitalisations and rehospitalisations for ambulatory care-sensitive conditions in Denmark: a population-based cohort study. BMJ Open 2015:5:e009878.

15. Wolff JL, Starfield B, Anderson G. Prevalence, expenditures, and complications of multiple chronic conditions in the elderly. Arch Intern Med 2002:162:2269-76.

16. Himelhoch S, Weller WE, Wu AW, et al. Chronic medical illness, depression, and use of acute medical services among medicare beneficiaries. Med Care 2004;42:512-21.

17. Payne RA, Abel GA, Guthrie B, et al. The effect of physical multimorbidity, mental health conditions and socioeconomic deprivation on unplanned admissions to hospital: a retrospective cohort study. CMAJ 2013;185:E221-8.

18. Prior A, Vestergaard M, Davydow DS, et al. Perceived stress, multimorbidity, and risk for hospitalizations for ambulatory caresensitive conditions: a population-based cohort study. Med Care 2017;55:131-9.

19. Dickens C, Katon W, Blakemore A, et al. Does depression predict the use of urgent and unscheduled care by people with long term conditions? A systematic review with meta-analysis. J Psychosom Res 2012;73:334-42.

20. Payne F. Utilization of out-of-hours services by patients with mental health problems. J Public Health Med 2000;22:302-6.

21. Stewart DE, Yuen T. A systematic review of resilience in the physically ill. Psychosomatics 2011;52:199-209.
22. Moth $G$, Olesen F, Vedsted P. Reasons for encounter and disease patterns in Danish primary care: changes over 16 years. Scand $J$ Prim Health Care 2012;30:70-5.

23. Andersen RM. Revisiting the behavioral model and access to medical care: does it matter? J Health Soc Behav 1995;36:1-10.

24. Katon W, Sullivan M, Walker E. Medical symptoms without identified pathology: relationship to psychiatric disorders, childhood and adult trauma, and personality traits. Ann Intern Med 2001;134:917-25.

25. Redelmeier DA, Tan SH, Booth GL. The treatment of unrelated disorders in patients with chronic medical diseases. N Engl J Med 1998;338:1516-20.

26. Rosendal M, Vedsted P, Christensen KS, et al. Psychological and social problems in primary care patients - general practitioners' assessment and classification. Scand J Prim Health Care 2013;31:43-9.

27. Christensen Al, Ekholm O, Glümer C, et al. The Danish National Health Survey 2010. Study design and respondent characteristics. Scand J Public Health 2012;40:391-7.

28. Pedersen CB, Gøtzsche H, Møller JO, et al. The Danish civil registration system. A cohort of eight million persons. Dan Med Bull 2006;53:441-9.

29. Christiansen T. Organization and financing of the Danish health care system. Health Policy 2002;59:107-18.

30. Velasco Garrido M, Zentner A, Busse R. The effects of gatekeeping: a systematic review of the literature. Scand J Prim Health Care 2011;29:28-38.

31. Pedersen KM, Andersen JS, Søndergaard J. General practice and primary health care in Denmark. J Am Board Fam Med 2012;25(Suppl 1):S34-S38.

32. Andersen JS, Olivarius NF, Krasnik A. The Danish National Health Service Register. Scand J Public Health 2011;39:34-7.

33. Kildemoes HW, Sørensen HT, Hallas J. The Danish National Prescription Registry. Scand J Public Health 2011:39(7 Suppl):38-41.

34. Cohen S, Kamarck T, Mermelstein R. A global measure of perceived stress. J Health Soc Behav 1983;24:385-96.

35. Cohen S, Williamson G. In. Perceived stress in a probability sample in the United States. In: Spacapan S, Oskamp S, eds. The social psychology of health. Newbury Park, CA: SAGE, 1988:31-67.

36. Lee EH. Review of the psychometric evidence of the perceived stress scale. Asian Nurs Res 2012;6:121-7.

37. Barnett K, Mercer SW, Norbury M, et al. Epidemiology of multimorbidity and implications for health care, research, and medical education: a cross-sectional study. Lancet 2012;380:37-43.

38. Huntley AL, Johnson R, Purdy S, et al. Measures of multimorbidity and morbidity burden for use in primary care and community settings: a systematic review and guide. Ann Fam Med 2012:10:134-41.

39. Diederichs C, Berger K, Bartels DB. The measurement of multiple chronic diseases--a systematic review on existing multimorbidity indices. J Gerontol A Biol Sci Med Sci 2011;66:301-11.

40. Valderas JM, Starfield B, Sibbald B, et al. Defining comorbidity: implications for understanding health and health services. Ann Fam Med 2009;7:357-63.

41. United Nations Educational, Scientific and Cultural Organization. International standard classification of education (ISCED). http:// www.uis.unesco.org/Education/Documents/isced-2011-en.pdf (accessed 10 Dec 2015)

42. Statistics Denmark. The Danish system for access to micro data. http://www.dst.dk/ext/645846915/0/forskning/Access-to-micro-dataat-Statistics-Denmark 2014--pdf (accessed 20 May 2015).

43. White IR, Royston P, Wood AM. Multiple imputation using chained equations: Issues and guidance for practice. Stat Med 2011;30:377-99.

44. Holmes TH, Rahe RH. The social readjustment rating scale. $J$ Psychosom Res 1967;11:213-8.

45. Folkman S, Lazarus RS. The relationship between coping and emotion: implications for theory and research. Soc Sci Med 1988;26:309-17.

46. McEwen BS, Stellar E. Stress and the individual. Mechanisms leading to disease. Arch Intern Med 1993;153:2093-101.

47. Barbosa-Leiker C, Kostick M, Lei M, et al. Measurement invariance of the perceived stress scale and latent mean differences across gender and time. Stress Health 2013;29:253-60.

48. Klinkman MS, Coyne JC, Gallo S, et al. False positives, false negatives, and the validity of the diagnosis of major depression in primary care. Arch Fam Med 1998;7:451-61.

49. Rothman KJ, Greenland S, Lash TL. Modern epidemiology. 3rd edn. Philadelphia, PA: Lippincott Williams \& Wilkins, 2008.

50. Bellón JA, Delgado-Sánchez A, de Dios Luna J, et al. Patient psychosocial factors and primary care consultation: a cohort study. Fam Pract 2007;24:562-9. 
51. Dowrick CF, Bellón JA, Gómez MJ. GP frequent attendance in Liverpool and Granada: the impact of depressive symptoms. Br J Gen Pract 2000;50:361-5.

52. Vedsted P, Fink P, Olesen F, et al. Psychological distress as a predictor of frequent attendance in family practice: a cohort study. Psychosomatics 2001;42:416-22.

53. Bellón JA, Delgado A, Luna JD, et al. Psychosocial and health belief variables associated with frequent attendance in primary care. Psychol Med 1999;29:1347-57.

54. Frostholm L, Fink P, Christensen KS, et al. The patients' illness perceptions and the use of primary health care. Psychosom Med 2005;67:997-1005

55. Gawronski KA, Kim ES, Miller LE. Potentially traumatic events and serious life stressors are prospectively associated with frequency of doctor visits and overnight hospital visits. J Psychosom Res 2014;77:90-6.

56. Smits FT, Brouwer HJ, Zwinderman AH, et al. Why do they keep coming back? Psychosocial etiology of persistence of frequent attendance in primary care: a prospective cohort study. J Psychosom Res 2014;77:492-503.

57. Gili M, Sesé A, Bauza N, et al. Mental disorders, chronic conditions and psychological factors: a path analysis model for healthcare consumption in general practice. Int Rev Psychiatry 2011;23:20-7.

58. van Oostrom SH, Picavet HS, de Bruin SR, et al. Multimorbidity of chronic diseases and health care utilization in general practice. BMC Fam Pract 2014;15:61.

59. van den Bussche H, Schön G, Kolonko T, et al. Patterns of ambulatory medical care utilization in elderly patients with specia reference to chronic diseases and multimorbidity--results from a claims data based observational study in Germany. BMC Geriatr 2011:11:54

60. Westert GP, Satariano WA, Schellevis FG, et al. Patterns of comorbidity and the use of health services in the Dutch population. Eur J Public Health 2001;11:365-72.

61. Gruneir A, Bronskill SE, Maxwell CJ, et al. The association between multimorbidity and hospitalization is modified by individual demographics and physician continuity of care: a retrospective cohort study. BMC Health Serv Res 2016;16:154.

62. Panagioti M, Stokes J, Esmail A, et al. Multimorbidity and patient safety incidents in primary care: a systematic review and metaanalysis. PLoS One 2015;10:e0135947.

63. Moth G, Vestergaard M, Vedsted P. Chronic care management in Danish general practice--a cross-sectional study of workload and multimorbidity. BMC Fam Pract 2012;13:52.
64. Langer S, Chew-Graham C, Hunter C, et al. Why do patients with long-term conditions use unscheduled care? A qualitative literature review. Health Soc Care Community 2013;21:339-51.

65. National Institute for Health and Care Excellence. Depression in adults: Recognition and management. https://www.nice.org.uk/ guidance/cg90/ (accessed 15 Nov 2016).

66. Danish Health Authority. National clinical guideline for the nonpharmacological treatment of unipolar depression quick guide. http://sundhedsstyrelsen.dk/da/udgivelser/2016/ /media/A5 35E69EE4994F7BA1170A70156C401D.ashx (accessed 15 Nov 2016).

67. Keizer E, Maassen I, Smits M, et al. Reducing the use of out-of-hours primary care services: a survey among Dutch general practitioners. Eur J Gen Pract 2016;22:189-95.

68. Remor E. Psychometric properties of a European Spanish version of the Perceived Stress Scale (PSS). Span J Psychol 2006;9:86-93.

69. Wang Z, Chen J, Boyd JE, et al. Psychometric properties of the Chinese version of the Perceived Stress Scale in policewomen. PLOS One 2011;6:e28610.

70. O'Brien R, Wyke S, Guthrie B, et al. An 'endless struggle': a qualitative study of general practitioners' and practice nurses' experiences of managing multimorbidity in socio-economically deprived areas of Scotland. Chronic IIIn 2011;7:45-59.

71. Mead N, Bower P. Patient-centredness: a conceptual framework and review of the empirical literature. Soc Sci Med 2000;51:1087-110.

72. Ivbijaro GO, Enum Y, Khan AA, et al. Collaborative care: models for treatment of patients with complex medical-psychiatric conditions. Curr Psychiatry Rep 2014;16:506.

73. Jani B, Bikker AP, Higgins M, et al. Patient centredness and the outcome of primary care consultations with patients with depression in areas of high and low socioeconomic deprivation. Br J Gen Pract 2012;62:576-81.

74. Mercer SW, Fitzpatrick B, Guthrie B, et al. The CARE Plus study - a whole-system intervention to improve quality of life of primary care patients with multimorbidity in areas of high socioeconomic deprivation: exploratory cluster randomised controlled trial and costutility analysis. BMC Med 2016;14:88.

75. Bohlmeijer E, Prenger R, Taal E, et al. The effects of mindfulnessbased stress reduction therapy on mental health of adults with a chronic medical disease: a meta-analysis. J Psychosom Res 2010;68:539-44.

76. Sharpe L, Gittins CB, Correia HM, et al. Problem-solving versus cognitive restructuring of medically ill seniors with depression (PROMISE- D trial): study protocol and design. BMC Psychiatry 2012;12:207. 